\title{
Studi Eksperimen Pengaruh Dimensi Pipa Kapiler Pada Sistem Air Conditioning Dengan Pre-Cooling
}

\author{
Awan Satya Darmawan dan Ary Bachtiar Khrisna Putra \\ Jurusan Teknik Mesin, Fakultas Teknologi Industri, Institut Teknologi Sepuluh Nopember (ITS) \\ Jl. Arief Rahman Hakim, Surabaya 60111 Indonesia \\ e-mail: arybach@me.its.ac.id
}

\begin{abstract}
Abstrak- Penggunaan air conditioner semakin banyak digunakan pada kehidupan sehari-hari diiringi dengan harga jual energi yang semakin mahal. Pada studi eksperimen kali ini mencoba mengoptimalisasi dan menigkatkan efisiensi energi pada sistem air conditioner dengan cara menambahkan satu buah evaporator dan satu buah pre-cooling, dimana pre-cooling dimanfaatkan untuk memanaskan air yang nantinya akan digunakan untuk keperluan rumah tangga. Pada sistem pengkondisian udara yang telah dimodifikasi tersebut maka dilakukan studi eksperimen dengan variasi panjang pipa kapiler, diameter pipa kapiler $\mathbf{d = 0 , 0 5 4}$ in, dengan panjang kapiler $1=35$ $\mathrm{cm}$, kapiler $2=65 \mathrm{~cm}$, kapiler $3=95 \mathrm{~cm}$. Hasil yang didapat dari studi eksperimen kali ini adalah semakin bertambahnya panjang pipa kapiler, kapasitas pendinginan evaporator, kerja kompresor dan COP dari sistem juga akan semakin kecil dan juga mengakibatkan temperatur masuk evaporator akan semakin kecil, yang akan mengakibatkan efek pendinginan akan semakin besar. Pada variasi pipa kapiler terpendek $35 \mathrm{~cm}$ menghasilkan data kapasitas pendinginan total sebesar 2,25 kW, kerja kompresor $0,433 \mathrm{~kW}$, temperatur masuk evaporator $7,26^{\circ} \mathrm{C}$, COP sebesar 5,21 dan HRR sebesar 1,16. Sedangkan pada variasi pipa kapiler terpanjang $95 \mathrm{~cm}$ kapasitas pendinginan total sebesar $0,72 \mathrm{~kW}$, kerja kompresor $0,332 \mathrm{~kW}$, temperatur masuk evaporator $1,64^{\circ} \mathrm{C}$, COP sebesar 4,35 dan HRR sebesar 1,26 .
\end{abstract}

Kata Kunci- Refrigerasi; pipa kapiler; efisiensi; modifikasi pengkondisian udara.

\section{PENDAHULUAN}

$\mathrm{D}$ I INDONESIA, konsumen alat pengkondisian udara dari tahun ke tahun semakin meningkat seiring dengan laju pertumbuhan ekonomi dan laju pertumbuhan penduduk dan juga dikarenakan negara kita yang beriklim panas, tetapi disisi lain tarif pembayaran listrik mengalami kenaikan yang cukup tinggi. Dalam upaya menurunkan tingkat konsumsi energi peralatan rumah tangga khususnya alat pengkondisian udara, salah satu alternatif yang dapat dilakukan adalah dengan mengoptimalisasi efisiensi energi pada air conditioner. Untuk dapat mengoptimalisasi dan meningkatkan efisiensi energy, maka dilakukan uji experimen dengan memodifikasi air conditioner menjadi multi evaporator dengan menambahkan satu evaporator dan satu alat pre-cooling.

Secara umum air conditioner yang ada di pasaran hanya menggunakan satu evaporator, dengan memodifikasi menjadi multi evaporator akan dihasilkan satu evaporator tambahan, sehingga alat pengkondisian udara tersebut memiliki dua evaporator untuk mengkondisikan udara pada dua ruangan. Selain satu evaporator tambahan, alat pengkondisian udara tersebut ditambahakan pre-cooling yang berguna sebagai kondensor tambahan agar dapat membantu kondensor utama untuk membuang kalor yang telah diserap oleh dua buah evaporator yang ada pada system selain itu pre-cooling juga diharapkan dapat meningkatkan COP sistem [7], kalor yang dibuang melalui pre-cooling akan dimanfaatkan untuk memanaskan air yang nantinya dapat dimanfaatkan untuk keperluan rumah tangga.

Pada air conditioner, expansion device yang biasa digunakan adalah pipa kapiler yang fungsinya untuk menurunkan tekanan dan mengontrol aliran refrijeran sesuai dengan kondisi yang dibutuhkan. Keuntungan dari pipa kapiler yaitu cukup sederhana dan harga pipa kapiler juga tidak terlalu mahal.

Agar efisiensi dapat mencapai maksimum, panjang dan diameter pipa kapiler harus tertentu, kompresor dan alat ekspansi harus mencapai kondisi hisap dan buang, yang memungkinkan kompresor memompa refrijeran dari evapotator yang sama besarnya dengan yang dilewatkan oleh alat ekspansi. Berkaitan dengan hal tersebut maka dilakukan serangakaian uji eksperimen pada air conditioner yang menggunakan refrigeran MC-22 dengan menggunakan beberapa dimensi panjang kapiler yang berbeda, yang hasilnya akan dianalisa pada eksperimen kali ini.

\section{URAIAN PENELITIAN}

\section{A. Sistem Refrigerasi}

Refrijerasi merupakan proses penyerapan kalor dari ruangan bertemperatur tinggi dan memindahkan kalor tersebut ke suatu medium tertentu tertentu yang bertemperatur lebih rendah sehingga didapatkan tercapainya suatu temperatur dan dipertahankannya termperatur tersebut di bawah temperatur lingkungan. Penyerapan dan pemindahan kalor ini menggunakan suatu medium yang disebut refrijeran.

Sistem refrijerasi adalah kombinasi kombinasi komponen, peralatan dan perpipaan, yang dihubungkan untuk menghasilkan efek pendinginan sehingga dapat menjadikan kondisi temperatur suatu ruangan berada di bawah temperatur 
semula. Pada prinsipnya dari sistem refrigerasi memanfaatkan prinsip dasar termodinmika dimana kalor bergerak dari temperatur tinggi ke temperatur rendah pada suatu media. Kondisi temperatur rendah yang dihasilkan oleh suatu sistem refrigerasi diakibatkan oleh penyerapan panas pada reservoir dingin yang merupakan salah satu bagian sistem refrigerasi tersebut. Panas yang diserap bersama-sama energi (kerja) yang diberikan kerja luar dibuang pada bagian sistem refrigerasi yang disebut reservoir panas.

\section{B. Modifikasi Sistem Refrigerasi Uap}

Sistem refrigerasi kompresi uap yang telah dimodifikasi adalah sistem yang memiliki komponen tambahan yaitu 1 unit evaporator dan 1 unit heat exchanger sebagai proses precooling.

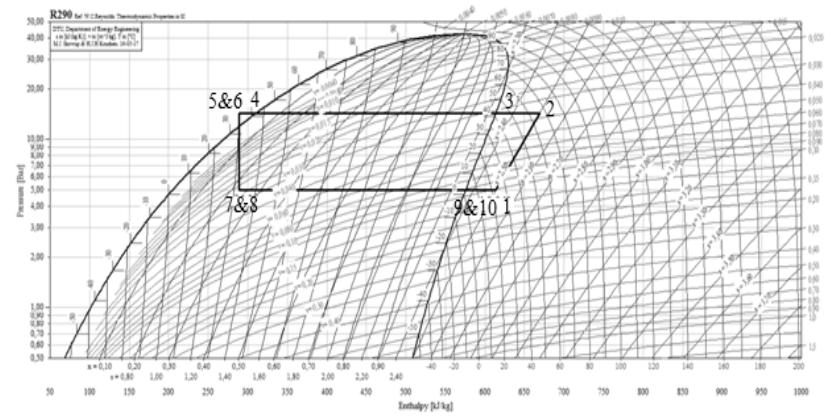

Gambar. 1. P-h Diagram Sistem Refrigerasi Uap yang Telah Dimodifikasi

Gambar 1 adalah gambar sistem kompresi uap yang sudah dimodifikasi sehingga terdapat beberapa komponen tambahan pada sistem tersebut. Berikut ini adalah proses-proses yang membentuk siklus kompresi uap yang telah dimodifikasi :

a. Proses 1-2: kompresi isentropi.

b. Proses 2-3: pelepasan kalor secara isobaris pada precooling, menyebabkan penurunan panas lanjut (desuperheating).

c. Proses 3-4: pelepasan kalor secara isobaris pada air cooled condensor, menyebabkan penurunan panas lanjut (desuperheating) dan proses pengembunan (kondensasi).

d. Proses 5 \& 6: titik percabangan sebelum masuk pipa kapiler 1 dan pipa kapiler 2 .

e. Proses 5-7: proses penurunan tekanan dengan isoentalpi pada pipa kapiler 1 .

f. Proses 6-8: proses penurunan tekanan dengan isoentalpi pada pipa kapiler 2.

g. Proses 7-9: penambahan kalor pada tekanan tetap pada evaporator 1, yang menyebabkan penguapan menuju uap jenuh atau uap panas lanjut (superheated).

h. Proses 8 - 10: penambahan kalor pada tekanan tetap pada evaporator 2, yang menyebabkan penguapan menuju uap jenuh atau uap panas lanjut (superheated).

\section{1) Kompresor}

Kompresor adalah jantung dari sistem kompresi uap karena fungsinya untuk memompa refrigeran agar tetap bersirkulasi di dalam sistem selain itu kompresor berfungsi untuk mengkompresi refrigeran uap agar mempunyai tekanan yang tinggi untuk memasuki kondensor..

$$
\dot{W}_{c}=\dot{m}\left(h_{2}-h_{1}\right)
$$

\section{2) Kondensor}

Kondensor Berfungsi sebagai alat penukar kalor, menurunkan temperatur refrigeran, dan mengubah wujud refrigeran dari fasa gas menjadi fasa cair. Kondensor berfungsi sebagai pembuang panas (heat rejection) dari dalam sistem ke luar sistem.

a) Kapasitas pre-cooling

$$
\dot{Q}_{\text {pre-cooling }}=\dot{m}\left(h_{2}-h_{3}\right)
$$

b) Kapasitas air cooled condensor

$$
\dot{Q}_{\text {cond }}=\dot{m}\left(h_{3}-h_{4}\right)
$$

\section{3) Evaporator}

Komponen ini berfungsi untuk menyerap panas dari ruangan. Panas tersebut diserap dan dialirkan melalu heat exchanger kemudian dipindahkan ke refrigeran.

a) Kapasitas evaporator 1

$$
\dot{Q}_{e 1}=\frac{\dot{m}}{2}\left(h_{9}-h_{7}\right)
$$

b) Kapasitas evaporator 2

$$
\dot{Q}_{e 2}=\frac{m}{2}\left(h_{10}-h_{8}\right)
$$

\section{4) Alat ekspansi}

Alat ekspansi menjadi komponen penentu dalam sistem pendinginan. Refrijeran pada fase cair dari kondensor yang akan diuapkan di evaporator dikontrol oleh alat ekspansi yang menyebabkan fasenya berubah menjadi campuran cair jenuh dan uap kemudian tekanannya pun juga ikut turun.

Pada penelitian kali ini alat ekspansi yang digunakan adalah pipa kapiler. Pipa kapiler merupakan pipa berdiameter kecil, karena ukuran diameternya yang lebih kecil dibandingkan pipa kondenser, hal ini akan menyebabkan penurunan tekanan akibat penyempitan aliran sehingga terjadi gesekan dan percepatan aliran refrigeran di dalam pipa kapiler. Proses ideal ekspansi berlangsung secara isoentalpi. Besarnya perubahan entalpi pada proses ekspansi adalah :

$$
h_{5}=h_{7}
$$

\section{Koefisien Unjuk Kerja (COP) Thermal}

Koefisien unjuk kerja (COP) thermal adalah unjuk kerja teoritis yang didapatkan dari perbandingan kalor yang diserap oleh evaporator dengan dayang yang dibutuhkan kompresor :

$$
\operatorname{COP}_{\text {thermal }}=\frac{\dot{Q}_{e} \text { total }}{\dot{W}_{c}}=\frac{\frac{\dot{m}}{2}\left(h_{9}-h_{7}\right)+\frac{\dot{m}}{2}\left(h_{10}-h_{8}\right)}{\dot{m}\left(h_{2}-h_{1}\right)}
$$

\section{Heat Rejection Ratio (HRR)}

Laju perpindahan panas pada kondensor jika kaitannya dengan kapasitas refrigerasi dinyatakan sebagai Heat Rejection Ratio (HRR) dapat dinyatakan dengan membagi 
besarnya kalor yang dilepaskan kondensor dibagi dengan besarnya kalor yang diserap oleh refrigeran.

$$
H R R=\frac{\dot{Q}_{c} \text { total }}{\dot{Q}_{e} \text { total }}=\frac{\dot{m}\left(h_{2}-h_{3}\right)+\dot{m}\left(h_{3}-h_{4}\right)}{\frac{\dot{m}}{2}\left(h_{9}-h_{7}\right)+\frac{\dot{m}}{2}\left(h_{10}-h_{8}\right)}
$$

\section{E. Heat Exchanger}

Alat penukar kalor (Heat Exchanger) merupakan sebuah alat yang berfungsi untuk menurunkan atau meningkatkan meningkatkan temperatur sebuah sistem dengan memanfaatkan suatu media pendingin atau pemanas sehingga kalor dapat berpindah dari temperatur tinggi ke temperatur rendah. Pada eksperimen kali ini heat exchanger yang dugunakan adalah jenis concentric tube dengan jenis aliran conter flow [5].

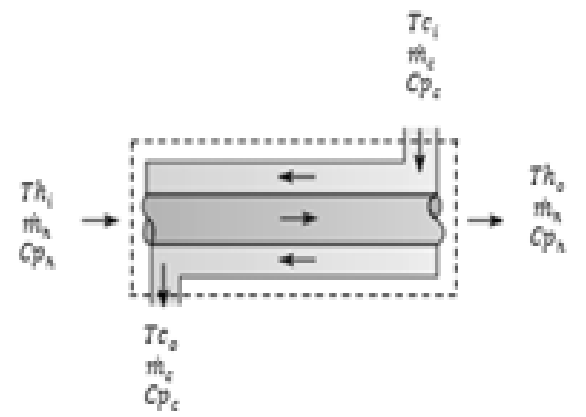

Gambar. 2. Concentric Tube Heat Exchanger Dengan Aliran Counter Flow

Untuk mengetahui kinerja heat exchanger maka dapat digunakan effectiveness dari heat exchanger itu sendiri. Untuk mencari hal tersebut maka harus diketahui nilai perpindahan kalor aktual dan perpindahan kalo maksimum $\left(\mathrm{q}_{\max }\right)$ atau perpindahan kalor yang diharapkan dari heat exchanger.

$$
\varepsilon=\frac{C_{c}\left(T_{c, o}-T_{c, i}\right)}{C_{\min }\left(T_{h, i}-T_{c, i}\right)}
$$

Untuk mengevaluasi kinerja Number of Transfer Units (NTU) heat exchanger tipe concentric tube dengan aliran counter flow digunakan perumusan sevagai berikut :

$$
N T U=\frac{1}{C_{r}-1} \ln \left(\frac{\varepsilon-1}{\varepsilon C_{r}-1}\right) \text { untuk }\left(\mathrm{C}_{\mathrm{r}}<1\right)
$$

\section{F. Penelitian Terdahulu}

Pada tahun 2012 Hernadi [1], telah melakukan penelitian “Analisa Pengaruh Panjang Pipa Kapiler 6m dan 3m Berdiameter 0,054 inch pada Mesin Pendingin Cascade Temperatur Rendah dengan Campuran Refrigeran Ethane dan $\mathrm{CO}_{2} ”$

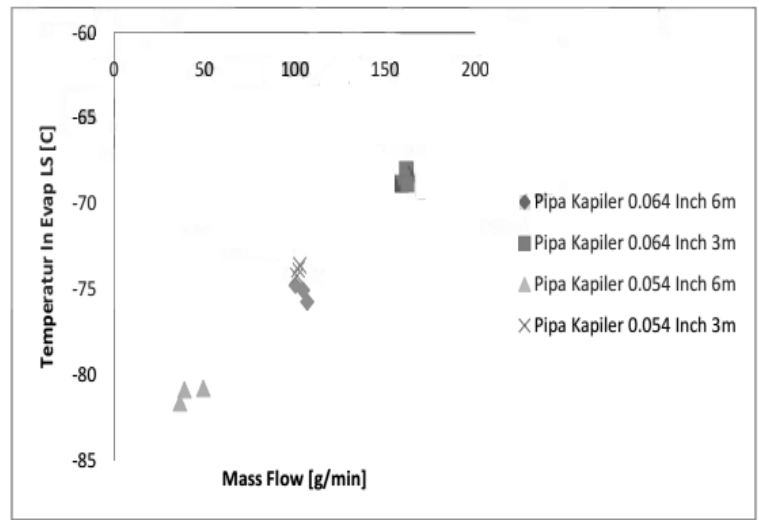

Gambar. 3. Grafik Perbandingan Temperatur in Evap dengan Mass Flow Rate

Dari gambar diatas menunjukan bahwa perubahan panjang serta diameter pipa kapiler sangat berpengaruh pada temperatur masuk evap LS dan laju aliran massa pada sistem. Penurunan temperatur masuk evap LS akan memperlambat laju aliran refrigeran pada sistem. Penurunan temperatur evap LS ini diakibatkan oleh penurunan tekanan yang dihasilkan oleh pipa kapiler dimana penurunan tekanan ini akan menghasilkan terperatur yang rendah, dimana semakin kecil diameter pipa kapiler dan semakin panjang pipa kapiler maka semakin rendah temperature yang dihasilkan.

\section{METODELOGI PENELITIAN}

\section{A. Skema Modifikasi Sistem Pengkondisian Udara}

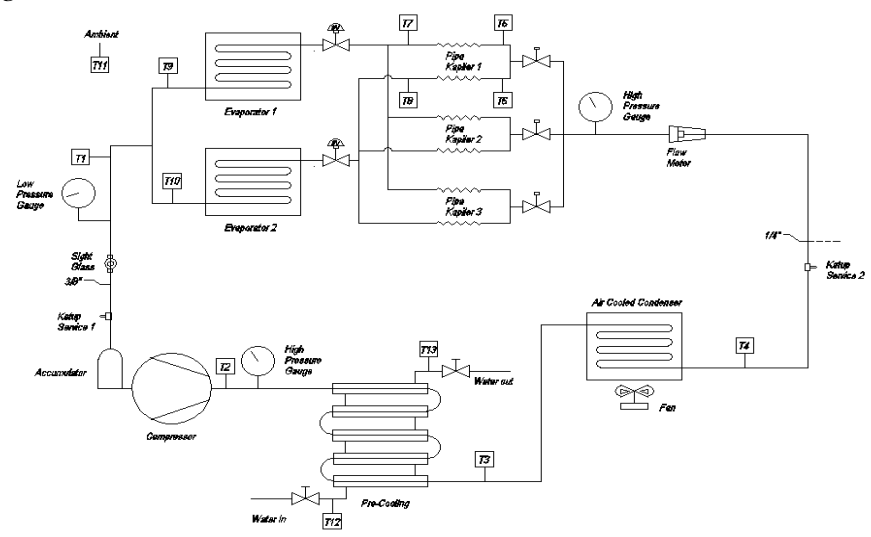

Gambar. 4. Skema Modifikasi Sistem Pengkondisian Udara 
Gambar 4 adalah sistem pengkondisian udara yang telah dimodifikasi yang terdapat beberapa komponen yaitu : kompresor, pre-cooling, air cooled condensor, 2 pipa kapiler dan 2 evaporator.

\section{B. Alat Ukur}

Berikut ini adalah alat ukur yang digunakan pada eksperimen kali ini :

1. Thermocouple tipe $\mathrm{K}:$ 13titik pengukuran temperatur.

2. Pressure Gauge : 2 high pressure dan 1 low pressure.

3. Flow meter

4. Amperemeter

5. Data akuisisi

\section{Prinsip Pengujian}

Pengujian pada sistem pengkondisian udara yang telah dimodifikasi pada kali ini menggunakan refrijeran Musicool-22 dengan tekanan suction kompresor sesuai rekomendasi dari PT. Pertamina yaitu 60Psig - 80 Psig [2]. Variasi panjang pipa kapiler yang digunakan adalah $35 \mathrm{~cm}$, $65 \mathrm{~cm}$ dan $95 \mathrm{~cm}$ dimana panjang pipa kapiler tersebut didapatkan dari software DanCap [3]. Pengambilan data dilakukan setelah sistem sudah dalam kondisi steady state dimana temperatur dan tekanan pada setiap titik pengukuran sudah tidak mengalami perubahan yang signifikan. Data yang diolah data rata-rata dari pengukuran pada saat sistem telah steady, ada 5 data yang diambil setiap 5 menit.

\section{HASIL DAN ANALISA}

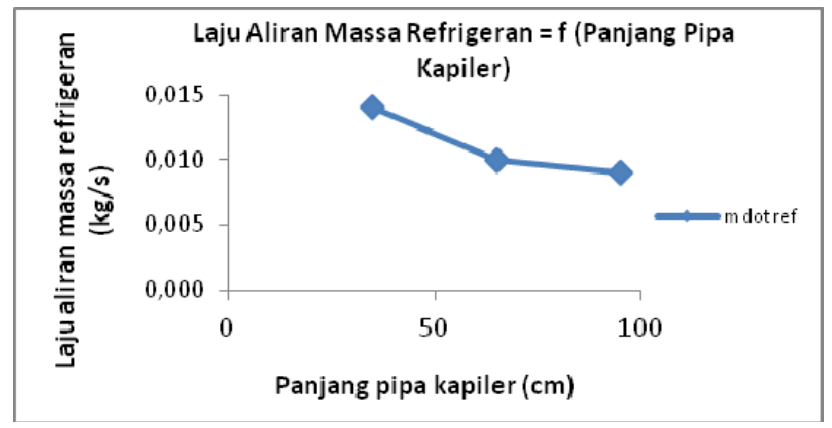

Gambar. 5. Grafik Laju Aliran Massa Refrigeran = f(Panjang Pipa Kapiler)

Grafik pada Gambar 5. menunjukkan trendline yang turun seiring dengan bertambahnya panjang pipa kapiler. Turunya laju aliran massa refrigeran seiring dengan bertambah panjangnya pipa kapiler disebabkan karena pertambahan panjang pipa kapiler akan mengakibatkan pressure drop semakin besar. Hal ini akan mengakibatkan head kompresor semakin besar juga sesuai dengan karakteristik kompressor maka kondisi ini akan mengakibatkan laju aliran massa pada kompresor turun.

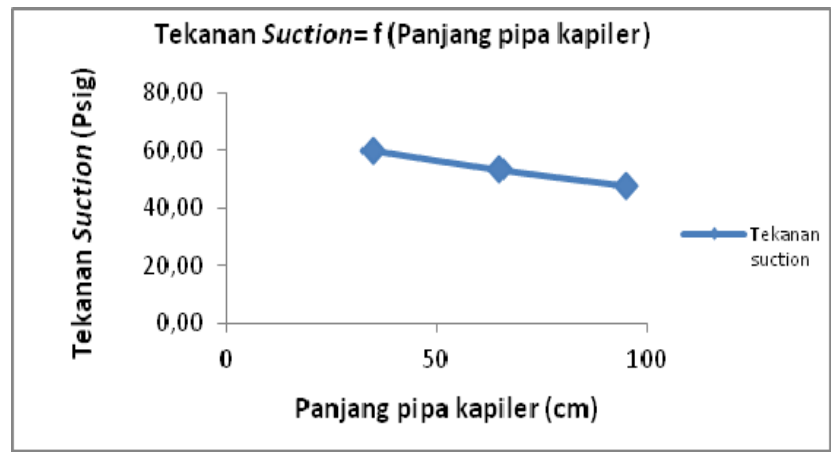

Gambar. 6. Grafik Tekanan Suction = f (Panjang Pipa Kapiler $)$

Grafik pada Gambar 6. menunjukkan trendline tekanan suction yang turun seiring dengan bertambahnya panjang pipa kapiler. Turunya tekanan suction kompresor disebabkan karena semakin panjang pipa kapiler memiliki pressure drop yang lebih besar sehingga mengakibatkan sekanan suction semakin rendah.yang akan diwisuda pada periode setelah pemuatannya.

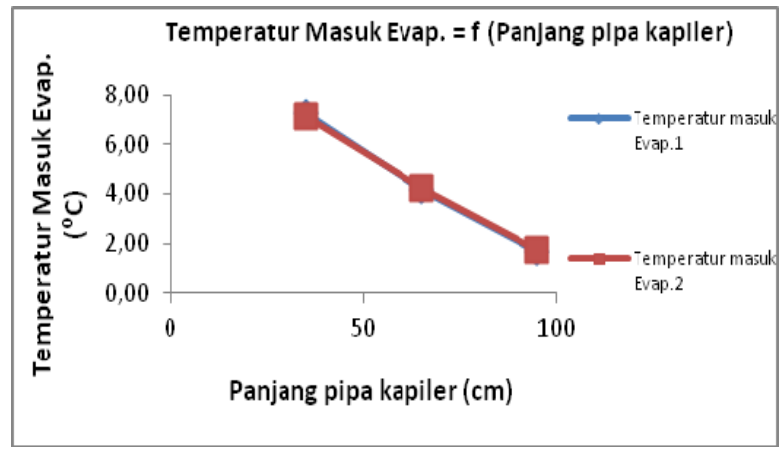

Gambar. 7. Grafik Temperatur Masuk Evap = f(Panjang Pipa Kapiler)

Grafik pada Gambar 7. menunjukkan trendline temperatur masuk evap yang turun seiring dengan bertambahnya panjang pipa kapiler. Turunya temperatur masuk evaporator seiring dengan bertambahnya panjang pipa kapiler disebabkan karena semakin panjang pipa kapiler akan mengakibatkan tekanan suction yang semakin kecil hal ini juga akan mengakibatkan temperatur masuk evaporator semakin rendah.

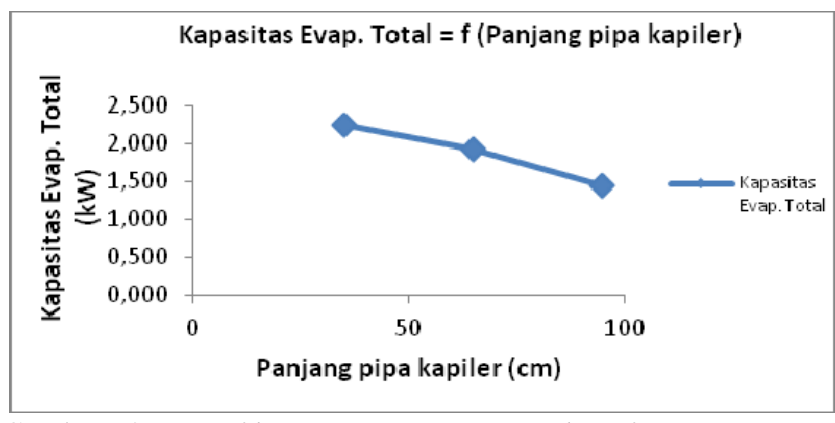

Gambar. 8. Grafik Kapasitas Evap Total $=f$ (Panjang Pipa Kapiler) 
Grafik pada Gambar 8. menunjukkan trendline kapasitas evap total yang turun seiring dengan bertambahnya panjang pipa kapiler. Turunya kapasitas evaporator seiring dengan bertambahnya panjang pipa kapiler disebabkan karena semakin panjang pipa kapiler memiliki mass flow rate yang semakin kecil kondisi ini akan mempengaruhi kapasitas evaporator karena nilai pengali berupa mass flow rate akan semakin kecil sehingga kapasitasnya menjadi kecil.

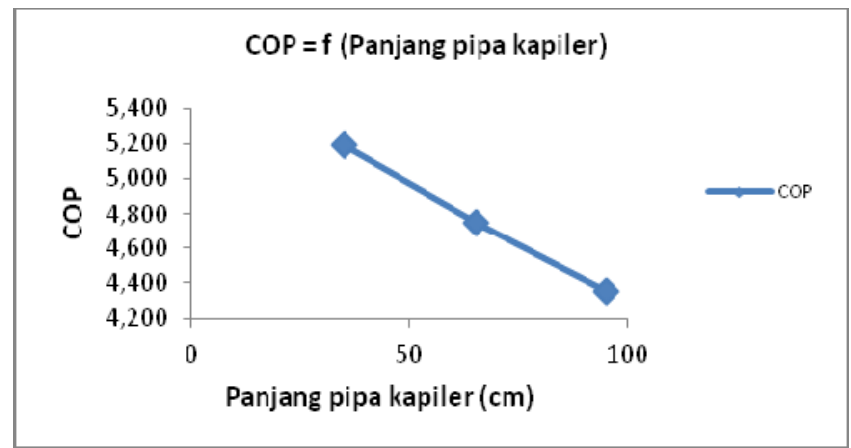

Gambar. 9. Grafik COP = f (Panjang Pipa Kapiler)

Grafik pada Gambar 10. menunjukkan trendline yang turun seiring dengan bertambahnya panjang pipa kapiler. Turunya nilai COP sistem seiring dengan bertambahnya panjang pipa kapiler disebabkan karena semakin panjang pipa kapiler memiliki mass flow rate yang semakin kecil, kondisi ini akan mempengaruhi kapasitas evaporator dan daya kompresor pada sistem menjadi semakin kecil juga, tetapi penurunan kapasitas evaporator tidak sebanding dengan penurunan kerja kompresor maka hal ini akan mengakibatkan nilai COP semakin kecil.

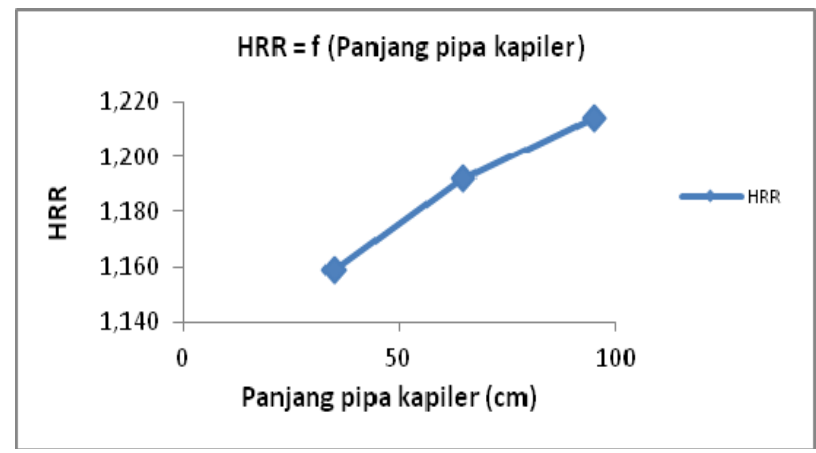

Gambar. 10. Grafik HRR = f(Panjang Pipa Kapiler)

Grafik pada Gambar 11. menunjukkan trendline yang naik. Naiknya HRR pada sistem disebabkan karena semakin panjang pipa kapiler memiliki mass flow rate yang semakin kecil, sehigga kapasitas evaporator dan kapasitas kondensor akan semakin kecil, tetapi pada pipa kapiler yang terpanjang memiliki temperatur yang lebih tinggi hal ini dikarenakan laju aliran massa yang lebih kecil akan membuat suhu refrigeran lebih tinggi dimana suhu yang makin tinggi akan membuat selihih entalpi semakin besar pada proses pelepasan kalor ke lingkungan sehingga penurunan laju aliran massa tidak sebanding dengan penurunan kapasitas konensor total. Hal ini akan berdampak semakin tinginya perbandingan antara kapasitas kondensor dengan kapasitas evaporator seiring dengan bertambah panjangnya pipa kapiler.

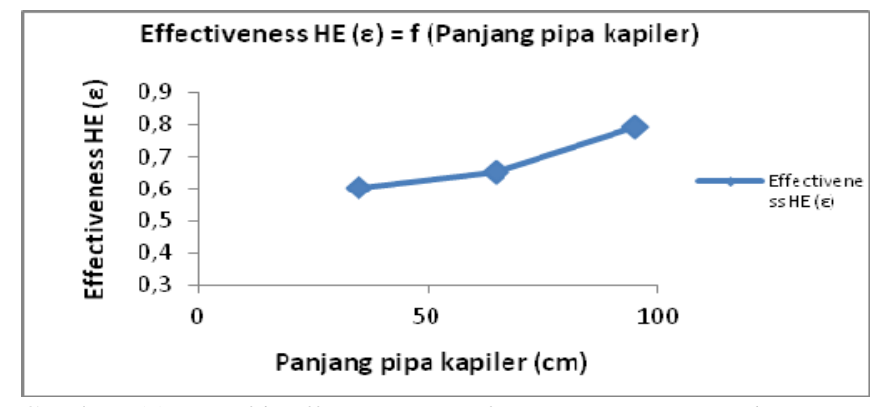

Gambar. 11. Grafik Effectiveness = f(Panjang Pipa Kapiler $)$

Grafik pada Gambar 12. menunjukkan trendline yang naik. Nilai effectiveness heat exchanger yang naik diakibatkan karena nilai q Sedangkan nilai $q_{\max }$ mengalami penurunan yang signifikan seiring dengan bertambah panjangnya pipa kapiler yang menyebabkan laju aliran massa refrigeran

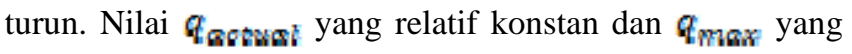
semakin menurun akan menyebabkan effectiveness heat exchanger semakin naik.

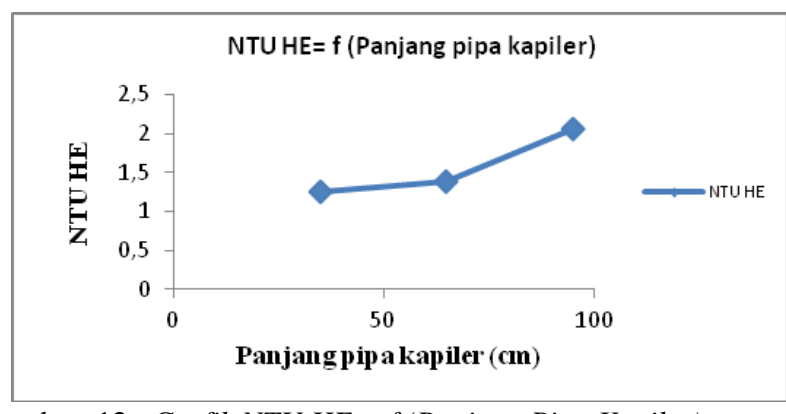

Gambar. 12. Grafik NTU HE = f(Panjang Pipa Kapiler)

Grafik pada Gambar 13. menunjukkan trendline yang naik. Naiknya nilai NTU pada sistem seiring dengan bertambahnya panjang pipa kapiler disebabkan karena turunnya laju aliran massa seiring dengan bertambah panjangnya pipa kapiler akan membuat nilai $\boldsymbol{C}_{\text {min }}$ semakin turun, sedangkan nilai $\boldsymbol{f}_{\max }$ relatif konstan hal ini akan membuat heat capacity ratio $\left(\boldsymbol{C}_{w}\right)$ semakin turun, turunya nilai $\left(\boldsymbol{C}_{p}\right)$ dan kenaikan nilai effectiveness yang tidak begitu signifikan akan membuat nilai NTU menjadi turun.

\section{KESIMPULAN}

Dari studi eksperimen yang telah dilakukan pada sistem pengkondisian uadara yang telah dimodifikasi dengan satu unit kompresor, satu unit pre-cooling, dan dua unit evaporator dengan menggunakan refrigeran MC-22, maka diperoleh beberapa kesimpulan sebagai berikut : 
1. Pada hasil analisa data nilai $C O P$ dan HRR dari sistem yang telah dimodifikasi adalah 5,21 dan 1,16.

2. Dengan melakukan variasi panjang pipa kapiler dapat disimpulkan sebagai berikut :

a. Laju aliran massa refrigeran terbesar pada variasi panjang pipa kapiler $35 \mathrm{~cm}$ yaitu $0,0067 \mathrm{~kg} / \mathrm{s}$.

b. Kerja kompresor terbesar pada variasi panjang pipa kapiler $35 \mathrm{~cm}$ yaitu $0,433 \mathrm{~kW}$.

c. Kapasitas evaporator terbesar pada variasi panjang pipa kapiler $35 \mathrm{~cm}$ yaitu 2,24 kW.

d. Temperatur terendah yang dapat dicapai pada masukan evaporator adalah pada variasi panjang pipa kapiler $95 \mathrm{~cm}$, temperatur masuk evaporator 1 adalah $1,64^{\circ} \mathrm{C}$ dan temperatur masukan evaporator 2 adalah $1,74^{\circ} \mathrm{C}$.

e. Nilai COP terbesar pada variasi pipa kapiler $35 \mathrm{~cm}$ yaitu 5,21.

3. Performa dari heat exchanger tipe concentric tube pada proses pre-cooling dapat diketahui dari nilai effectiveness dan NTU. Nilai effectiveness dan NTU semakin naik seiring dengan bertambah panjangnya pipa kapiler, pada panjang pipa kapiler terpanjang yaitu $95 \mathrm{~cm}$ memiliki nilai effectiveness sebesar 0,795 dan NTU sebesar 2,066

\section{DAFTAR PUSTAKA}

[1] Hernandi, 2012, “Analisa Pengaruh Panjang Pipa Kapiler 6m dan 3m Berdiameter 0,054 inch pada Mesin Pendingin Cascade Temperatur Rendah dengan Campuran Refrigeran Ethane dan $\mathrm{CO}_{2}$ ”. Depok, Universitas Indonesia.

[2] http://www.pertamina.com/our-business/hilir/pemasaran-danniaga/produk-dan-layanan/solusi-bisnis/gasproduk/musicool/musicool-22/

[3] http://refrigerationandairconditioning.danfoss.com/supportcenter/apps-and-software/dancap/

[4] Moran, M.J and Howard N. Shapiro, 2000, "Fundamental of Engineering Thermodynamics”. John Wiley \& Sons Inc. Chicester.

[5] P.Incropera, Frank., P.Dewitt, David., L.Bergman, Theodore, S.Lvine, Adrienne.,"Fundamental of Heat and Mass Transfer Seventh Edition”, Asia, John Wiley \& Sons (Asia) Pte Ltd.

[6] Stoecker, Wilbert F., and Jones, Jerold W.,1982, "Refrigerasi dan Pengkondisian Udara edisi kedua”. Jakarta, Indonesia, Erlangga.

[7] Rustadi, Rudi, 2013, "Pemanfaatan Air Kondensat Dari Evaporator Yang Biasa Terbuang Untuk Meningkatkan Unjuk Kerja AC Split”. Politeknik Negeri Bandung.

[8] Firdaus, Aneka., 2010, "Analisa Pengaruh Penggunaan Refrigeran Hidrkarbon Musicool-22 Pengganti Freon-22 Terhadap Kinerja Alat Air Conditionig”, Seminar Tahunan Teknik Mesin, ISBN, Sriwijaya University, Palembang-Indonesia. 